Research Article

\title{
Dissolution of (1-3),(1-4)- $\beta$-Glucans in Pressurized Hot Water: Quantitative Assessment of the Degradation and the Effective Extraction
}

\author{
Óscar Benito-Román, Alexandra Martín-Cortés, María José Cocero, and Esther Alonso \\ Departamento de Ingeniería Química y TMA, Escuela de Ingenierías Industriales, Universidad de Valladolid, \\ Calle Doctor Mergelina s/n, 47011 Valladolid, Spain
}

Correspondence should be addressed to Esther Alonso; ealonso@iq.uva.es

Received 19 March 2016; Accepted 3 May 2016

Academic Editor: Robert J. Linhardt

Copyright (C) 2016 Óscar Benito-Román et al. This is an open access article distributed under the Creative Commons Attribution License, which permits unrestricted use, distribution, and reproduction in any medium, provided the original work is properly cited.

\begin{abstract}
The purpose of this work was to study the behavior of (1-3)(1-4)- $\beta$-D-glucan in pressurized hot water. For this purpose, solid $\beta$ glucan $(450 \mathrm{kDa})$ was put in water and heated at different temperatures $\left(120,150\right.$, and $\left.170^{\circ} \mathrm{C}\right)$ for different times $(5$ to 360 minutes). At $120^{\circ} \mathrm{C}$ it was found that the highest soluble $\beta$-glucan concentration was measured after 60 minutes; at 150 and $170^{\circ} \mathrm{C}$ optimal times were 45 and 20 minutes, respectively. The maximum amount of $\beta$-glucan dissolved in each of the optimal conditions was 1.5, 2.2 , and $2.0 \mathrm{~g} / \mathrm{L}$, respectively. Under those conditions an important reduction was observed in the molecular weight: at $120^{\circ} \mathrm{C}$ and $60 \mathrm{~min}$ it was $63 \mathrm{kDa}$; at $150^{\circ} \mathrm{C}$ and $45 \mathrm{~min}$ it was reduced down to $8 \mathrm{kDa}$; and at $170^{\circ} \mathrm{C}$ and $20 \mathrm{~min}$ it was only $7 \mathrm{kDa}$. Besides this reduction in the MW some hydrolysis products, such as glucose and HMF, were observed. These results revealed the convenience of using PHW to dissolve $\beta$-glucans since the operation times, compared to the conventional process $\left(55^{\circ} \mathrm{C}, 3 \mathrm{~h}\right)$, were reduced despite the fact that the MW was significantly reduced once the $\beta$-glucan was dissolved; therefore, PHW can be used to extract $\beta$-glucans from barley under controlled conditions in order to prevent severe degradation.
\end{abstract}

\section{Introduction}

$\beta$-glucan, a D-glucose linear homopolymer, is the major fiber constituent of barley. In $\beta$-glucans, $\mathrm{D}$-glucose is linked to other two or three units by means of $\beta$-(1-4)-O-glycosidic linkage (forming cellobiose or cellotriose blocks) which in turn are separated by a $\beta$-(1-3)-O-glycosidic linkage. The presence of this 1-3 linkage alters the linear structure of the polymer, allowing the water to get into the different $\beta$ glucan chains being soluble in water as a consequence. The final solubility properties of the $\beta$-glucan are affected by a number of parameters referring to the molecular structure [1]: the ratio $\beta-(1-4) / \beta-(1-3)$ linkages; the length of the $\beta$-(14) structures; and the molecular weight.

There are an important number of extraction procedures of $\beta$-glucan and according to Vasanthan and Temelli [2] can be classified in two types: dry (based on milling procedures) and wet. Wet extraction processes are the most common and simple since they use water or alkali solutions at temperatures in the range $40-75^{\circ} \mathrm{C}$. In all those works it has been seen that the extractability of $\beta$-glucans is increased with the temperature [3]. Benito-Román et al. [3] also reported that the $\beta$-glucan extraction is mass transfer limited, so high stirring rates and small particle sizes of barley are needed. Increases in the temperature when extracting $\beta$ glucan from barley present two parallel effects: the increase of $\beta$-glucan extractability and the gelification of starch [4]. The gelification of starch occurs at temperatures above $63^{\circ} \mathrm{C}$, phenomena easily recognizable since the viscosity of the extraction media increases dramatically due to the sharp rise in the concentration of dissolved starch (rising from $0.1 \%$ to $1 \%$ [3]). High viscosities reduce the efficiency of the stirring and hence the extraction of $\beta$-glucan is hindered. Therefore, a new extraction method that helps to increase the $\beta$-glucan extraction rate reducing the amount of starch in one single step is required. In this sense the use of pressurized hot water 
(PHW) appears to be an attractive alternative to increase the solubility of $\beta$-glucans and to avoid mass transfer limitations due to its special features.

The term PHW refers to the water in liquid state in the range $100^{\circ} \mathrm{C}$ (boiling point) and $374^{\circ} \mathrm{C}$ (critical temperature of water) by the application of pressure. Properties of water (density, ionic strength, viscosity, and surface tension) change dramatically when changing pressure and specially temperature. For instance, the ionic product increases from $10^{-14}$ at room temperature to $10^{-11.59}$ at $155^{\circ} \mathrm{C}$ and 20 bar [5]. This leads to an increase in the concentration of the hydronium ions which promote the hydrolysis reactions [6]. PHW also presents lower viscosity but higher diffusivity than water at room temperature, which favors the diffusion into the vegetal matrix and the release of compounds [7]. Due to the above-mentioned properties PHW has been used with two different purposes: first, as an extraction media to recover bioactive compounds (phenolics, diterpenes among others [6], or polysaccharides from natural matrixes [811]) due to its enhanced transport properties. The second main use of PHW has been as a reaction media to study the hydrolysis of polysaccharides (i.e., starch) from biomass to obtain the monomers (hexoses when the substrate is starch or cellulose; or pentoses from arabinoxylans). Then the degradation kinetics of these compounds have been studied $[12,13]$ as well as the behavior (solubility and physical properties) of the monomers in pressurized water [14].

All the above-mentioned enhanced transport properties reveal the potential of $\mathrm{PHW}$ to be used to extract $\beta$-glucans from barley. As a previous step to the extraction study it is necessary to perform one dissolution study in order to quantify the way the high temperatures and pressures affect $\beta$-glucans and starch (since it is the major component of barley and the major coextracted compound with the $\beta$ glucan). Therefore, the purpose of the present work is to quantify the extent of degradation that these molecules suffer as a function of the working conditions. A solid product concentrated in $\beta$-glucans (36.5\% and $25.4 \%$ of starch) was used, since all the mass transfer limitations derived from the water diffusing into the solid matrix and the release of the polysaccharide had to be avoided. The concentration of starch and $\beta$-glucans reached under different conditions was measured and the molecular weight of the $\beta$-glucans was also measured in order to quantify the extent of hydrolysis it was suffering.

\section{Materials and Methods}

2.1. Raw Material. A high molecular weight $\beta$-glucan concentrate $(36.5 \%$ in $\beta$-glucan (molecular weight $450 \mathrm{kDa}$ ) and $25.4 \%$ in starch) was used in this study. This concentrate was obtained in our laboratory, using waxy barley $(4.8 \%$ in $\beta$ glucan and $52.0 \%$ in starch, both in dry basis) as primary source of $\beta$-glucan. Barley was pretreated with ethanol under reflux for two hours (flour to ethanol $(80 \% \mathrm{v} / \mathrm{v})$ ratio of 1 to 6$)$ in order to deactivate $\beta$-glucanases and obtain a high MW $\beta$ glucan. The isolation procedure was done at $55^{\circ} \mathrm{C}$ for 3 hours using water as solvent, according to [3]. The liquid extract obtained was dried by means of the Mobile Minor Spray
Dryer (GEA NIRO, Denmark). The most significant operating conditions were as follows: dry air inlet temperature, $160^{\circ} \mathrm{C}$; outlet temperature $87-90^{\circ} \mathrm{C}$; atomization wheel spinning at $21000 \mathrm{rpm}$; and sample flow rate to the dryer about $1 \mathrm{~L} / \mathrm{h}$. After all this isolation procedure a dry fine powder rich in $\beta$-glucans was obtained.

2.2. Experimental Device. All the experiments were carried out in a $30 \mathrm{~mL}$ internal volume High-Pressure View Chamber (Eurotechnica GmbH, Germany). The maximum operating pressure and temperature of this device are 300 bar and $500^{\circ} \mathrm{C}$, respectively. It consists of two sections: the view chamber where water is introduced and the pressure and temperature are adjusted, and the area where the solid sample (that has been previously compressed to form a pill, which had an approximate weight of 0.5 gram) is introduced. This area is filled up with water at room temperature and pressurized. These two zones are separated by a valve; once the desired conditions of pressure and temperature in the chamber are achieved, the valve is opened and the sample is introduced in the view chamber (where stirring can be provided). Finally, after the experiment is concluded a sample of the liquid extract can be taken in order to analyze the compounds that have been dissolved and formed during the experiment.

2.3. Chemical Analysis. Megazyme International Ltd. "Mixed-linkage $\beta$-glucan" and "Total Starch" assay kits were used to quantify $\beta$-glucan and starch, respectively. Both species were measured in the liquid extract following the standard procedure modifications proposed by Megazyme International Ltd. (Ireland). The concentration of $\beta$-glucan dissolved was reported in $g$ of $\beta$-glucan $/ 100 \mathrm{~g}$ of water. In the mass balance calculations, the variations in density that water experiences when changing temperature and pressure were considered, which results in variations in mass of water introduced in the chamber. Starch dissolved was analyzed following a modification of the general protocol: "starch is present in a soluble form and D-glucose and maltodextrins are present." Results were expressed in $\mathrm{mg} / \mathrm{L}$.

Molecular weight of $\beta$-glucan was determined by Size Exclusion Chromatography (HPLC-SEC) using a chromatography system that consisted of an isocratic pump (Waters 1515), an automatic injector (Waters 717), guard column (Shodex SB-G), and a GPC column (Shodex OHpak SB804HQ) and a differential refractive index detector (Waters 410). The column was kept at $35^{\circ} \mathrm{C}$, and flow rate of the mobile phase $\left(0.1 \mathrm{M} \mathrm{NaNO}_{3}+0.02 \% \mathrm{NaN}_{3}\right)$ was set at $0.5 \mathrm{~mL} \cdot \mathrm{min}^{-1}$. The $\beta$-glucan molecular weight standards were purchased from Megazyme International Ltd. (Ireland) and were in the range $40-359 \mathrm{kDa}$.

For the measurement of oligosaccharides and sugars (cellobiose, fructose, glucose, and HMF) formed in the extraction process, HPLC was used. Chromatography system was essentially the same used for MW determination (pump, injector, and detector, including an UV/Visible Detector Waters 2489); column and guard column were purchased from Shodex (model KS-802, guard column KS-G) and set at $60^{\circ} \mathrm{C}$ and mobile phase (MilliQ water) was set at $0.8 \mathrm{~mL} \cdot \mathrm{min}^{-1}$. 


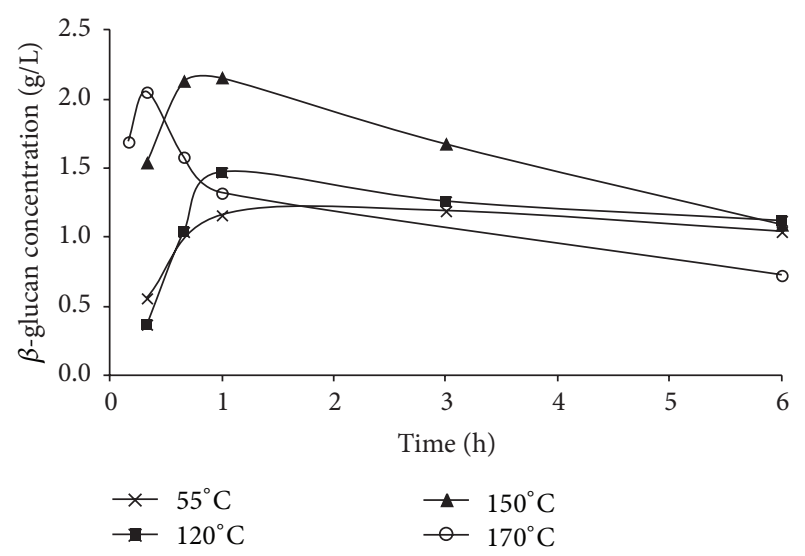

Figure 1: Time evolution of the concentration of $\beta$-glucan at different temperatures and 20 bar of pressure.

2.4. Experimental Procedure. In all the experiments a $0.5 \mathrm{~g}$ pill of $\beta$-glucan concentrate was introduced in the view chamber $(30 \mathrm{~mL})$, where it was vigorously stirred. Temperature was changed from 120 to $170^{\circ} \mathrm{C}$ and the experiments lasted from 5 minutes to 6 hours. In order to keep water in liquid state in all the experiments pressure was kept at 20 bar. Also some experiments at $55^{\circ} \mathrm{C}$ and 20 bar were done. They were used as control and basis for the comparison with the results obtained in pressurized hot water. After the experiment a $15 \mathrm{~mL}$ sample was taken and used to analyze $\beta$-glucan, starch, and sugars/oligosaccharides contents. This sample was also used to determine the molecular weight of the $\beta$-glucan dissolved after being exposed to the high temperatures and pressures.

To evaluate the combined and simultaneous effect to time and temperature the severity factor was introduced and calculated according to

$$
R_{0}=t \cdot \exp \left(\frac{T-100}{14.75}\right)
$$

\section{Results and Discussion}

3.1. Dissolution of $\beta$-Glucan. The effect of temperature and time on the $\beta$-glucan dissolution was studied in this section. The experiments were done at 120,150 , and $170^{\circ} \mathrm{C}$ and lasted from 5 minutes to 6 hours. In order to keep water in liquid state, pressure was set at 20 bar. A control experiment was performed ( $55^{\circ} \mathrm{C}, 20$ bar and 5 minutes to 6 hours). Results can be observed in Figure 1.

In general terms, and according to Figure 1, it can be seen that the higher the temperature the more $\beta$-glucan dissolved. At $55^{\circ} \mathrm{C}$ the highest concentration in the liquid extract was obtained after 3 hours $(1.2 \mathrm{~g} / \mathrm{L})$; longer extraction experiments did not increase the amount of $\beta$-glucan dissolved; in fact the concentration of $\beta$-glucan began to decline very slightly. The similar trend was observed when the extraction of $\beta$-glucan from barley was carried out in a stirred tank at atmospheric pressure at $55^{\circ} \mathrm{C}$ : the maximum extraction yield was $47.2 \%$ after three hours (corresponding to a concentration of $2.3 \mathrm{~g} / \mathrm{L}$ ) but decreased to $44.3 \%$ when
TABLE 1: $\beta$-glucan maximum concentration and molecular weight obtained in the optimal conditions using PHW as solvent (pressure 20 bar).

\begin{tabular}{lcccc}
\hline$T\left({ }^{\circ} \mathrm{C}\right)$ & $t(\min )$ & $\log \left(R_{0}\right)$ & $\beta$-glucan $(\mathrm{g} / \mathrm{L})$ & $\mathrm{MW}(\mathrm{kDa})$ \\
\hline 55 & 180 & - & 1.2 & 400 \\
120 & 60 & 2.37 & 1.5 & 63 \\
150 & 45 & 3.13 & 2.2 & 8 \\
170 & 15 & 3.24 & 2.0 & 7 \\
\hline
\end{tabular}

the extraction lasted 5 hours [3]. According to these results, an increase in pressure at low temperatures does not enhance the solubility of $\beta$-glucans in water. However, when temperature was increased above $100^{\circ} \mathrm{C}$ two different phenomena were observed according to Figure 1: first, the maximum amount of $\beta$-glucan was increased significantly at $120^{\circ} \mathrm{C}$ and dramatically above $150^{\circ} \mathrm{C}$ compared to the results obtained at $55^{\circ} \mathrm{C}$; second, this maximum amount of $\beta$-glucan dissolved was achieved in much shorter times, in all the cases below 1 hour. This represents a reduction of more than two hours compared to the low temperature experiment. After this maximum, the concentration of $\beta$-glucans began to decrease in a very fast way: the higher the temperature the faster the decrease.

It can be seen that PHW helps to increase the amount of $\beta$-glucan dissolved with a reduction of the time required, as summarized in Table 1: at $120^{\circ} \mathrm{C}$ the maximum concentration was detected after 60 minutes; at $150^{\circ} \mathrm{C}$ it was after 45 minutes and at $170^{\circ} \mathrm{C}$ only 15 minutes were required to have the highest concentration of $\beta$-glucans.

These results represent a clear linear correlation between time and temperature: the higher the temperature the lower time required to get the highest concentration of $\beta$-glucans; however, from that linear correlation a maximum theoretical temperature to be used for the $\beta$-glucan dissolution was calculated and resulted in being around $185^{\circ} \mathrm{C}$. The presence of this temperature limit can be explained using Figure 1: when using water at temperatures above $120^{\circ} \mathrm{C}$ a completely different pattern of dissolution is observed compared to that registered at $55^{\circ} \mathrm{C}$. At high temperatures two zones can be distinguished: a first one where a rapid increase of the amount of $\beta$-glucan dissolved is observed until a maximum value of concentration is reached. The time to get the maximum is shorter when the temperature is higher, but this does not mean that the shorter the time the higher the concentration, as shown in Figure 1. The second zone is found after the maximum, where the concentration of $\beta$-glucan begins to decrease. The concentration of $\beta$-glucan dissolved after six hours converges in the value $1 \mathrm{~g} / \mathrm{L}$, regardless of the temperature. After a closer analysis of the two observed zones, it can be concluded that the first zone would indicate the dissolution period, and this period is shorter when temperature is increased. On the other hand, the second zone would indicate the degradation of the $\beta$-glucan already dissolved. In order to verify this hypothesis, the main degradation products will be studied and results presented in Section 3.3.

From these experimental results it can be concluded that temperature accelerates the dissolution of $\beta$-glucan, probing 


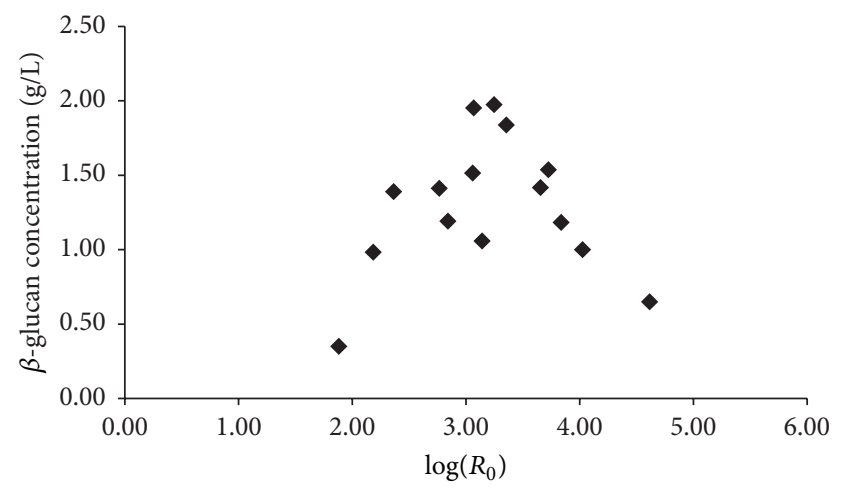

Figure 2: $\beta$-glucan concentration versus the logarithm of the severity factor.

the clear relationship between the time to get the highest concentration and the temperature. It also shows the second effect that the increase of temperature has on polysaccharides: their degradation. The concentration of $\beta$-glucans decreased with the time of exposure at all the tested temperatures. The specific effect that each one of the variables has on the $\beta$-glucan dissolution is not very clear, since at $170^{\circ} \mathrm{C}$, despite of the short times to get the maximum concentration, the maximum concentration measured is lower than that achieved at $150^{\circ} \mathrm{C}$. This would indicate that, at short times, the effect of temperature on the degradation of the $\beta$-glucans is greater than on the dissolution: hydrolysis begins to be faster than dissolution and the final concentration of $\beta$-glucans is lower. Therefore, the theoretical maximum calculated at $185^{\circ} \mathrm{C}$ would indicate that the hydrolysis of the $\beta$-glucan is as fast as its dissolution, and no $\beta$-glucan would be detected under those conditions. In order to verify this and to evaluate the simultaneous effect that time and temperature have on the concentration of the $\beta$-glucan dissolved, concentration of $\beta$-glucan versus the logarithm of the severity factor was represented, resulting in Figure 2.

The highest value of $\beta$-glucan concentration corresponds to a $\log R_{0}$ of 3.2 (approximately $150^{\circ} \mathrm{C}$ and 60 minutes extraction time). The combined effect of temperature and time is strong on the $\beta$-glucan concentration as it can be seen in Figure 1; high intensity conditions tend to degrade the $\beta$ glucan.

3.2. Evolution of the Starch Concentration. In the conventional extraction process the starch coextraction was seen as one of the major drawbacks to increase the extraction temperature, since the increase of the temperature (above $63^{\circ} \mathrm{C}$ ) led to the gelatinization of starch despite the increase in $\beta$-glucan solubility. The behavior of the starch at high temperatures it is not well known, and therefore it is necessary to perform this study. The starch concentration in the liquid at the studied temperatures can be observed in Figure 3. At high temperatures starch presents relatively high concentrations in very short times; afterwards, concentration begins to decrease dramatically. After one hour of experiment starch concentration decreased dramatically. Concentration remained almost constant and below $100 \mathrm{ppm}$ after 1 hour

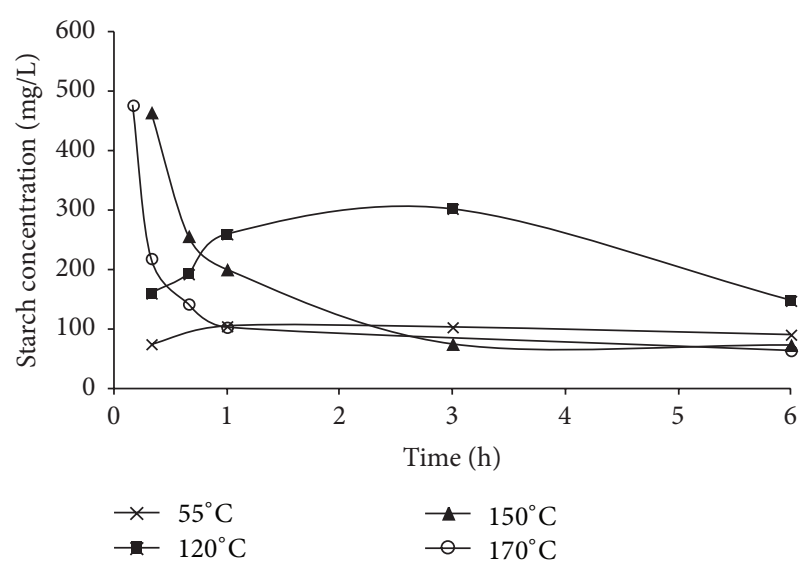

FIgURE 3: Time evolution of the concentration of the starch dissolved at different temperatures.

at $170^{\circ} \mathrm{C}$ and after 3 hours at $150^{\circ} \mathrm{C}$. A different trend was observed at $120^{\circ} \mathrm{C}$, where the maximum amount of starch was observed after three hours; from that moment on a rapid decrease in concentration was observed. A quite similar trend was observed at $55^{\circ} \mathrm{C}$ but the concentration of starch was significantly lower.

At high temperatures starch dissolution is very fast, but almost immediately hydrolysis occurs, probing the rapid decrease in concentration. At medium temperatures dissolution is slower and the amount of starch dissolved is significantly lower.

This behavior of starch will have to be evaluated when using barley as raw material, but as it can be seen in Figures 1 and 3, high temperatures help to increase the amount of $\beta$-glucan dissolved decreasing the concentration of dissolved starch. In PHW starch is degraded rapidly, much faster than $\beta$-glucans; therefore, gelatinization will not happen and will not hinder the extraction of $\beta$-glucans.

3.3. Hydrolysis By-Products. As a consequence of the exposure to the high temperatures for long times, the degradation of the polysaccharides ( $\beta$-glucan and starch) may occur. This hydrolysis process is very complex since different types of reaction are taking place: hydrolysis, isomerization, bond cleavage, and dehydration [12]. However, it is possible to identify some key degradation compounds: cellobiose, which has given the structure of $\beta$-glucans based on cellotriosyl and cellobiose blocks [1] that would indicate a first step in the depolymerization process of the $\beta$-glucan; other compounds such as glucose and fructose (that might appear as a consequence of an isomerization process of the glucose that only happens at high temperatures [12]) represent the second stage in the degradation of the polysaccharides and finally the presence of 5-hydroxymethyl-2-furaldehyde (HMF) would indicate the complete degradation of the hexoses [13]. The presence of this compound makes the solution have a dark color; the more the concentration the darker the solution. Figure 4 shows the evolution in the color of solutions at different temperatures after one hour of processing. 


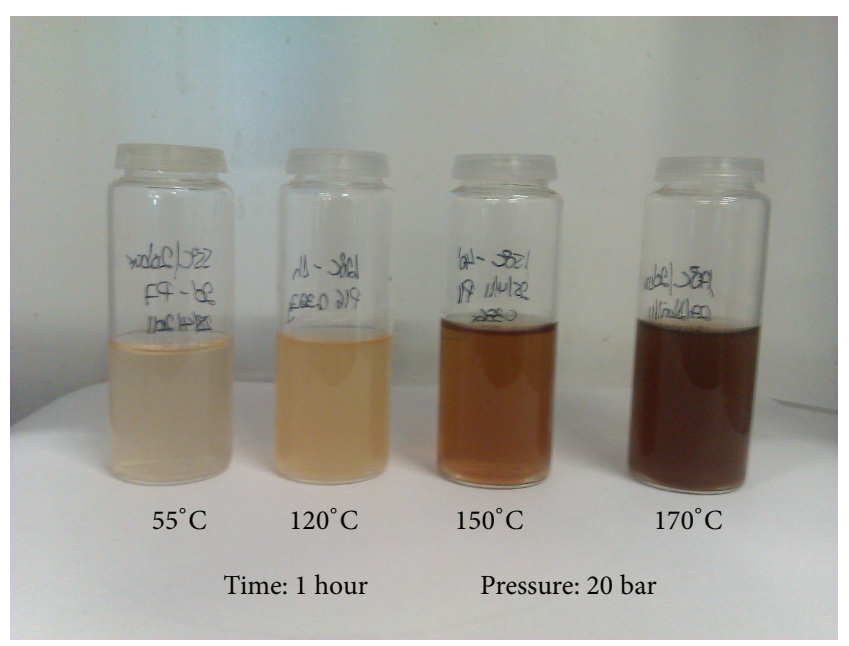

FIGURE 4: Effect of temperature on the color of liquid extract, after 1 hour (pressure 20 bar).

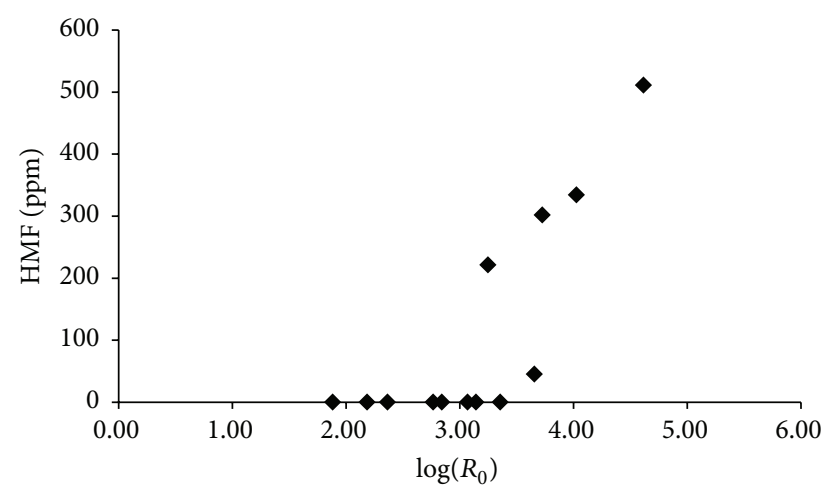

FIGURE 5: HMF concentration versus the logarithm of the severity factor.

HMF was only detected in the experiments where the $\log R_{0}$ was greater than 3.2 (this corresponds to a condition of $150^{\circ} \mathrm{C}$ and more than 60 minutes). At $170^{\circ} \mathrm{C}$ was also detected and in much higher concentrations. The practical limit for the dissolution of the $\beta$-glucan in PHW is the presence of HMF. To avoid its presence, temperature should be kept around $150^{\circ} \mathrm{C}$ and times below 60 minutes; under these conditions the amount was of $\beta$-glucan is maximized, the starch concentration is clearly lower than that of $\beta$-glucan, and the complete degradation of $\beta$-glucan has happened. HMF concentration versus the logarithm of the severity factor is represented in Figure 5.

As the optimal temperature seems to be $150^{\circ} \mathrm{C}$, the main degradation products will be presented for this temperature. Glucose and cellobiose concentrations are the most significant as it is shown in Figure 6.

Cellobiose concentration presents a slight decrease along the extraction process; as concentration remains almost constant, $\beta$-glucan degradation is quite limited. This means that the increase in the glucose concentration can be attributed to the degradation of starch, whose concentration decreases along the time. Glucose concentration keeps decreasing, as

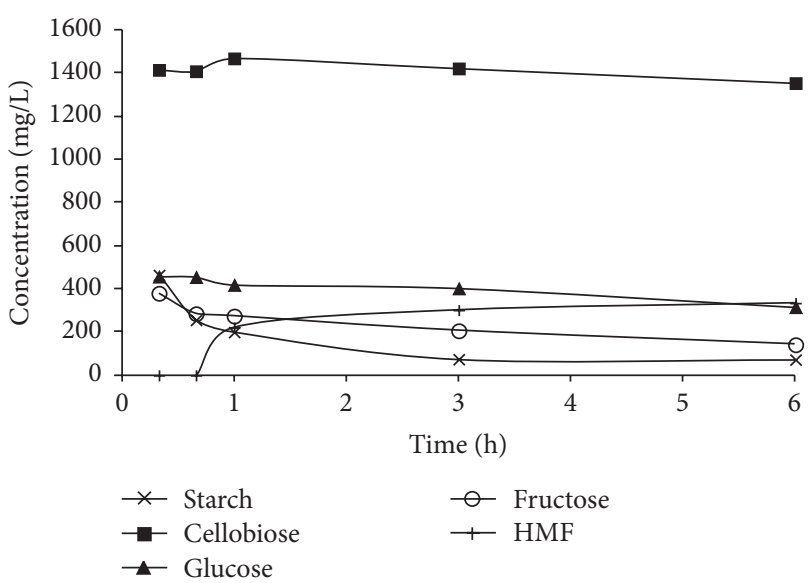

FIgURE 6: Time evolution of the concentration of several degradation products at $150^{\circ} \mathrm{C}$.

well as fructose; meanwhile, HMF concentration is increasing as well as other degradation products such as pyruvaldehyde.

3.4. Effect on the Molecular Weight. For each temperature an optimum time was found in order to maximize the concentration of $\beta$-glucans in the liquid phase. It was $75 \mathrm{~min}$ for $120^{\circ} \mathrm{C}$; $45 \mathrm{~min}$ for $150^{\circ} \mathrm{C}$, and $20 \mathrm{~min}$ for $170^{\circ} \mathrm{C}$. Under these conditions a new experiment was performed to check the effect that these conditions of time and temperature have on molecular weight. Results are summarized in Table 1. It can be seen how temperature helps in the loss of molecular weight; this reduction in molecular weight can be good for applications that require low molecular weight $\beta$-glucans. PHW would help to decrease the molecular weight of the $\beta$ glucans without the requirement of an enzyme or other more complex ways that can be found in the literature (enzymatic treatment; ultrasounds, gamma irradiation). But in the cases that $\beta$-glucans are required with high MW, a careful selection of the extraction conditions will have to be done, in order to preserve it.

\section{Conclusions}

The aim of the present work was to study the behavior of $\beta$-glucans and starch in water at high temperatures and quantify the extent of degradation that suffers as a function of the working conditions. It was seen that water at high temperatures helps to decrease the required time to dissolve $\beta$-glucans and to decrease the amount of starch dissolved. High temperatures $\left(170^{\circ} \mathrm{C}\right)$ help to achieve the maximum amount of dissolved $\beta$-glucan at shorter times, below 10 minutes; even though the maximum amount solubilized is lower than that at $150^{\circ} \mathrm{C}(2.2 \mathrm{~g} / \mathrm{L})$. The best conditions were $150^{\circ} \mathrm{C}$ and times below $45 \mathrm{~min}$. Once the $\beta$-glucan is dissolved, it begins to be degraded (reduction in the MW and presence of degradation compounds such as HMF); degradation is faster for higher temperatures. A significant reduction in the molecular weight was observed: initially it was $450 \mathrm{kDa}$; after $45 \mathrm{~min}$ at $150^{\circ} \mathrm{C}$ it was $8 \mathrm{kDa}$ and $7 \mathrm{kDa}$ after $20 \mathrm{~min}$ at $170^{\circ} \mathrm{C}$. 
These results will be useful to delimit the experimental range in terms of temperature (from 120 to $170^{\circ} \mathrm{C}$ ) and time (from 20 to $60 \mathrm{~min}$ ) to be used in the extraction of $\beta$-glucans from barley. In that case, it will be necessary to evaluate not only the solubility but also how PHW helps to overcome the mass transfer limitations in the extraction from the vegetable matrix and the way that molecular weight is affected, as the vegetable matrix and the endogenous $\beta$-glucanases are affected.

\section{Competing Interests}

The authors declare that they have no competing interests.

\section{Acknowledgments}

The authors want to thank University of Valladolid for FPIUVa Fellowship and Junta de Castilla y León for the economic support (Research Project GR11-2008).

\section{References}

[1] A. Lazaridou and C. G. Biliaderis, "Molecular aspects of cereal $\beta$-glucan functionality: physical properties, technological applications and physiological effects," Journal of Cereal Science, vol. 46, no. 2, pp. 101-118, 2007.

[2] T. Vasanthan and F. Temelli, "Grain fractionation technologies for cereal beta-glucan concentration," Food Research International, vol. 41, no. 9, pp. 876-881, 2008.

[3] O. Benito-Román, E. Alonso, and S. Lucas, "Optimization of the $\beta$-glucan extraction conditions from different waxy barley cultivars," Journal of Cereal Science, vol. 53, no. 3, pp. 271-276, 2011.

[4] P. J. Wood, I. R. Siddiqui, and D. Paton, "Extraction of highviscosity gums from oats," Cereal Chemistry, vol. 55, pp. 10381049, 1978.

[5] IAPWS, "The International Association for the Properties of Water and Steam," 2016, http://www.iapws.org/newform.html.

[6] M. Plaza and C. Turner, "Pressurized hot water extraction of bioactives," TrAC-Trends in Analytical Chemistry, vol. 71, pp. 39-54, 2015.

[7] C. C. Teo, S. N. Tan, J. W. H. Yong, C. S. Hew, and E. S. Ong, "Pressurized hot water extraction (PHWE)," Journal of Chromatography A, vol. 1217, no. 16, pp. 2484-2494, 2010.

[8] A. U. Buranov and G. Mazza, "Extraction and characterization of hemicelluloses from flax shives by different methods," Carbohydrate Polymers, vol. 79, no. 1, pp. 17-25, 2010.

[9] J. E. Cacace and G. Mazza, "Pressurized low polarity water extraction of lignans from whole flaxseed," Journal of Food Engineering, vol. 77, no. 4, pp. 1087-1095, 2006.

[10] M. Mukhopadhyay and P. Panja, "A novel process for extraction of natural sweetener from licorice (Glycyrrhiza glabra) roots," Separation and Purification Technology, vol. 63, no. 3, pp. 539545, 2008.

[11] C. Pronyk and G. Mazza, "Design and scale-up of pressurized fluid extractors for food and bioproducts," Journal of Food Engineering, vol. 95, no. 2, pp. 215-226, 2009.

[12] B. M. Kabyemela, T. Adschiri, R. M. Malaluan, and K. Arai, "Glucose and fructose decomposition in subcritical and supercritical water: detailed reaction pathway, mechanisms, and kinetics," Industrial \& Engineering Chemistry Research, vol. 38, no. 8, pp. 2888-2895, 1999.

[13] S. H. Khajavi, Y. Kimura, T. Oomori, R. Matsuno, and S. Adachi, "Degradation kinetics of monosaccharides in subcritical water," Journal of Food Engineering, vol. 68, no. 3, pp. 309-313, 2005.

[14] M. D. A. Saldaña, V. H. Alvarez, and A. Haldar, "Solubility and physical properties of sugars in pressurized water," The Journal of Chemical Thermodynamics, vol. 55, pp. 115-123, 2012. 

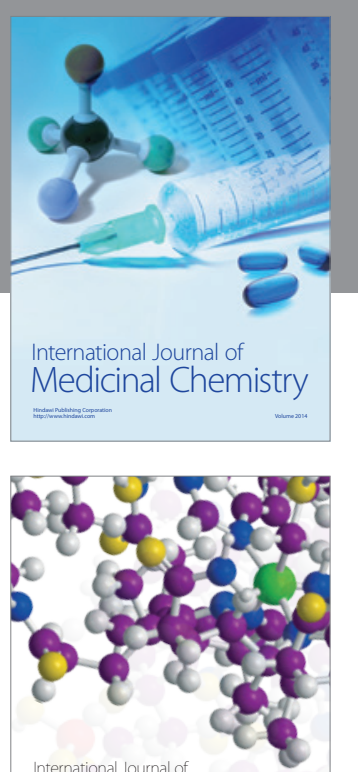

Carbohydrate Chemistry

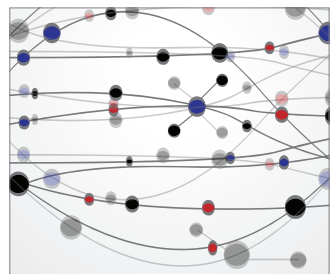

The Scientific World Journal
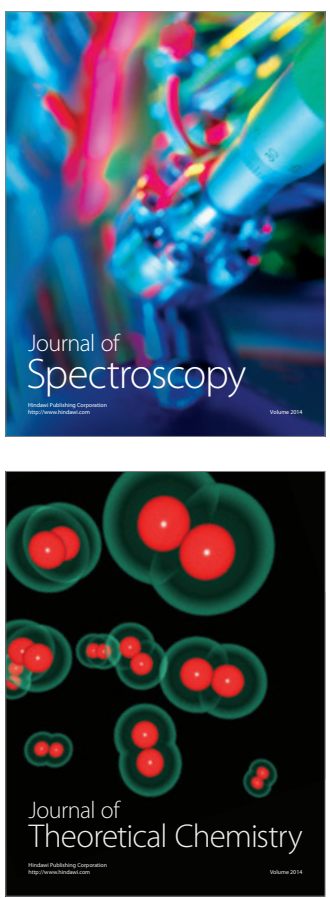
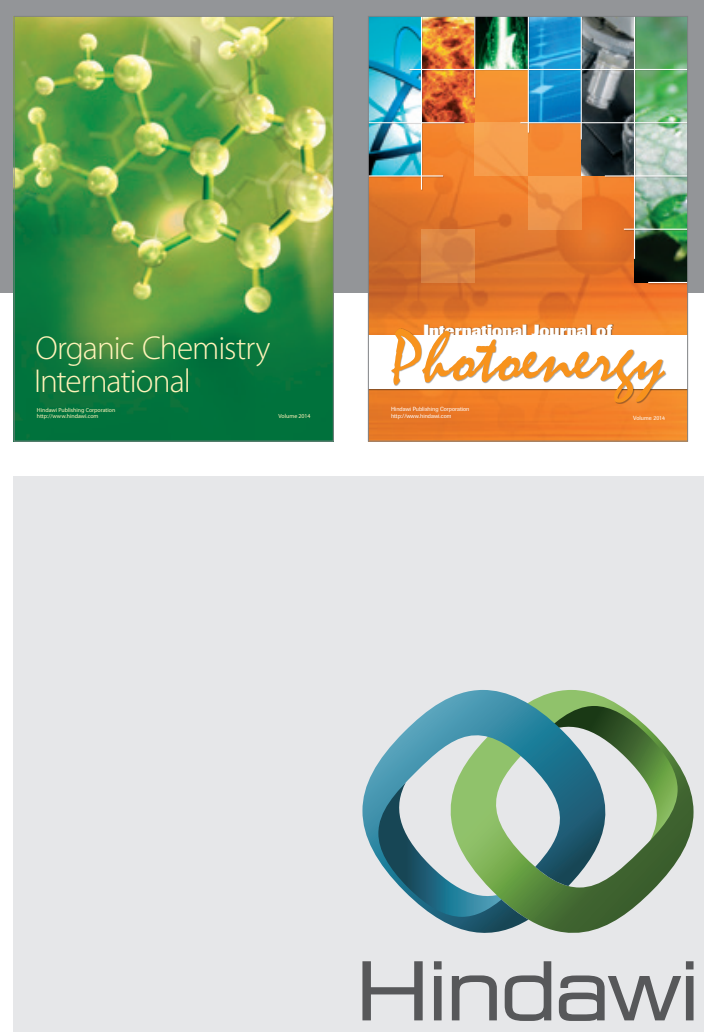

Submit your manuscripts at

http://www.hindawi.com

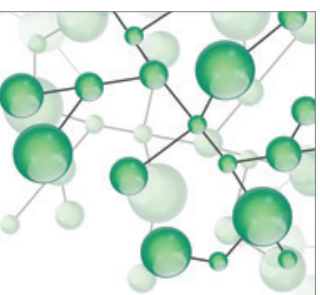

International Journal of

Inorganic Chemistry

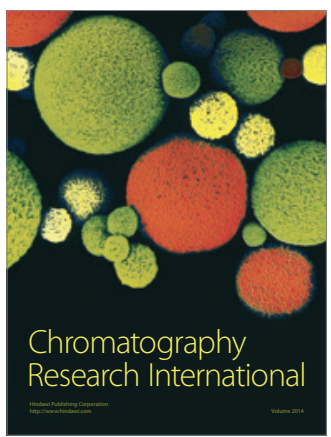

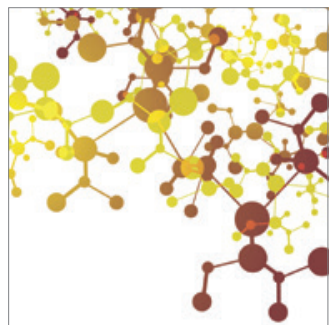

Applied Chemistry
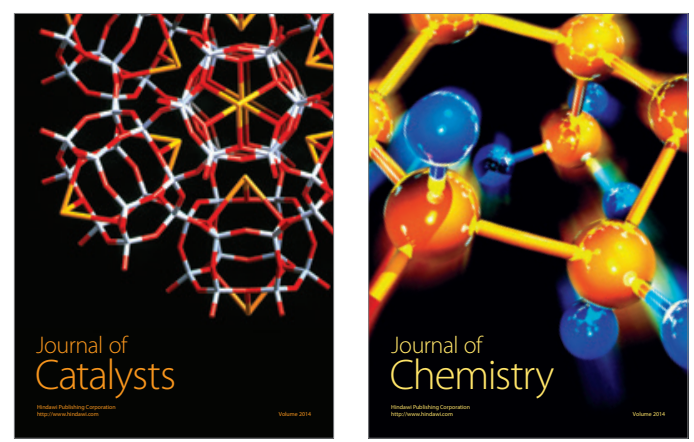
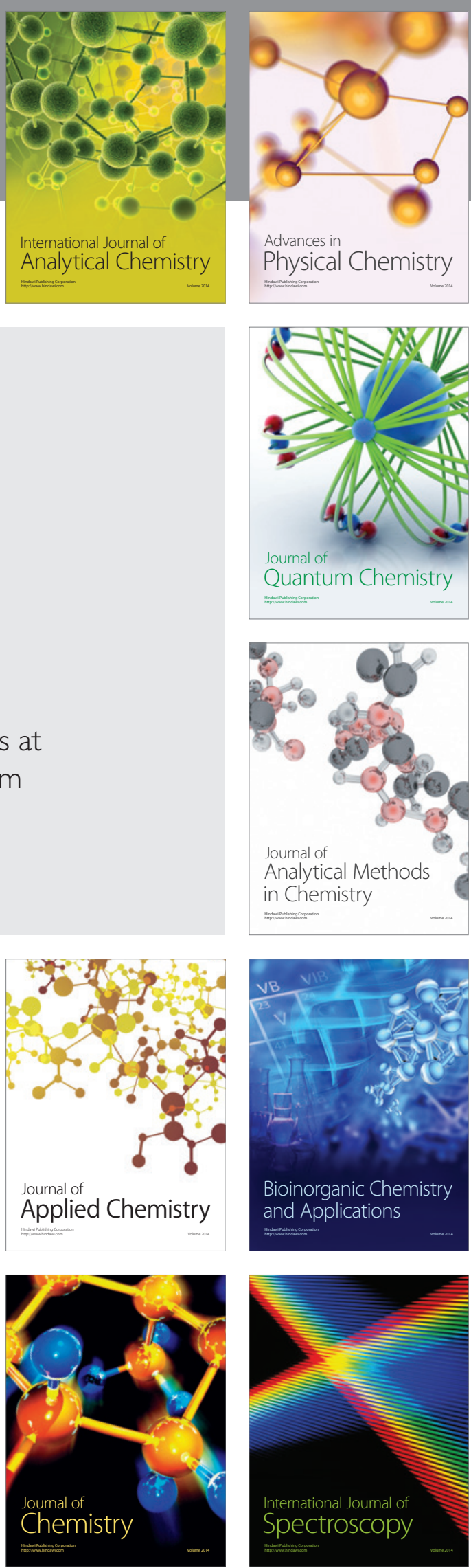